\title{
Analysis of self medication practice among medical undergraduates: a study in tertiary care teaching hospital, Bareilly
}

\author{
Richa Bhardwaj, Kauser Sayedda*, Quazi Shahir Ahmed
}

\begin{abstract}
Department of Pharmacology, Shri Ram Murti Smarak Institute of Medical Sciences, Bareilly, Uttar Pradesh, India
\end{abstract}

Received: 26 December 2016

Revised: 27 December 2016

Accepted: 30 January 2017

*Correspondence to:

Dr. Kauser Sayedda,

Email: ksayedda96@gmail.com

Copyright: (C) the author(s), publisher and licensee Medip Academy. This is an openaccess article distributed under the terms of the Creative Commons Attribution NonCommercial License, which permits unrestricted noncommercial use, distribution, and reproduction in any medium, provided the original work is properly cited.

\begin{abstract}
Background: Self medication is becoming a most prevalent practice among educated people across the world. In today's era, internet and media is one of the most important sources for promoting self medication practice. Medical students are highly influenced with this practice. Many drugs can have significant unwanted effects. This may result in serious clinical effects with potential life-threatening complications. Objective of the study was to find out the self medication practice and its details among medical undergraduates of SRMSIMS, a tertiary care teaching hospital, Bareilly.

Methods: During the study period $1^{\text {st }}, 2^{\text {nd }}$ and $3^{\text {rd }}$ prof. of MBBS students were included in the study. Sample size was 348 . They were asked to fill printed semi structured validated questionnaire which consist of straight forward multiple type questions. The duration of study was March $22^{\text {nd }} 2015$ to $29^{\text {th }}$ March 2015 . Results: Out of 300 students, 60\% $(n=180)$ students were male and $40 \%$ $(n=120)$ were females. Among them $94 \%(n=282)$ gave positive response and $6 \%(n=18)$ gave negative response to self-medication. Antibiotics were the most common class of drug self medicated by the majority of participants $(80 \%)$ while the most common illness was fever $(70 \%)$.

Conclusions: It was concluded that more than half of strength of students are likely to take self-medication for various illnesses; the reason might be the awareness of drugs due to easy accessibility of information through books, internet pharmacy and through media too. So, essential measure should be taken to reduce the practice of self medication among students to avoid development of drug dependence, resistance and drug interactions.
\end{abstract}

Keywords: Antibiotics, Medical undergraduates, Self medication

\section{INTRODUCTION}

As stated by WHO "Self-medication is the selection and use of medicines by individuals to treat self recognized illness or symptoms." It is becoming the most prevalent practice among medical students. It involves the usage of medicines without seeking prescription from the physician to treat self recognized disorders or symptoms but it can differ from self care because it can be harmful also. ${ }^{1}$ It includes self pharmacological treatment, nondrug self-treatment, social support in illness, and first aid in everyday life.

The World Health Organization (WHO), reported about self-medication that sub-optimal prescribing practices such as inadequate dosing, incomplete treatment courses and indiscriminate drug use have contributed to the emergence and spread of antimicrobial resistance. ${ }^{2}$

A survey on widely advertised medications indicated that the majority of college students used at least one of the advertised products, without discussing this with their physicians. ${ }^{3}$

In several studies, it has been found that inappropriate self-medication causes wastage of resources, increases resistance of pathogens and generally causes serious health hazards such as adverse drug reactions, prolonged suffering and drug dependence. ${ }^{1,4}$ Medical students have easy access to various information regarding the illness through literatures and medical books to medicate and diagnose themselves. 
In today's era, internet and media is one of the most important sources for promoting self medication practice. Young students are highly influenced with this practice. Many drugs can have significant unwanted effects. This may result in serious clinical effects with potential lifethreatening complications. Therefore, the diagnosis by the physician is very important for the proper treatment. The pharmacist in a community pharmacy has an important role in recommending drugs for selfmedication.

The pharmacist should distinguish between patients for whom pharmacists could recommend the drugs and patients who should be encouraged to consult physicians. With the time self medication practice is inflating day by day. Though it is associated with many problems like disease not being diagnosed properly, wrong drug and incorrect dosage of the drug which can lead to progression of the disease along with complications. So, students from medical background assume self medication as a special significance as they are the future medical practioners and also, they are well exposed to the drugs and diseases. This practice has both pros and cons depending upon the situation of the disease and patients. The present study was, therefore, conducted to analyse the self medication practice among undergraduates of Shri Ram Murti Smarak Institute of Medical Sciences, Bareilly.

\section{METHODS}

Design of the study was a cross-sectional, questionnairebased study.

\section{Study participants}

During the study period, three batches of MBBS students were included in the study. Sample size was 348. They were asked to fill printed semi structured validated questionnaire which consist of straight forward multiple type questions. The duration of study was March $22^{\text {nd }}$ 2015 to $29^{\text {th }}$ March 2015.

\section{Ethical issues}

Prior permission was obtained from the Ethics Committee of the Institution for conducting the study. The purpose of the study was explained to the participating students and confidentiality was ensured.

\section{RESULTS}

Out of all participants enrolled in the study, 300 successfully filled the questionnaire. Out of those, $60 \%$ $(n=180)$ students were male and $40 \% \quad(n=120)$ were females. Among them 94\% $(\mathrm{n}=282)$ gave positive response and $6 \%(n=18)$ gave negative response to selfmedication (Figure 1). Among these 300 students, 33\%, $35 \%$ and $32 \%$ were studying in their first professional, second professional and third professional (part 1and 2) respectively (Table 1$)$.

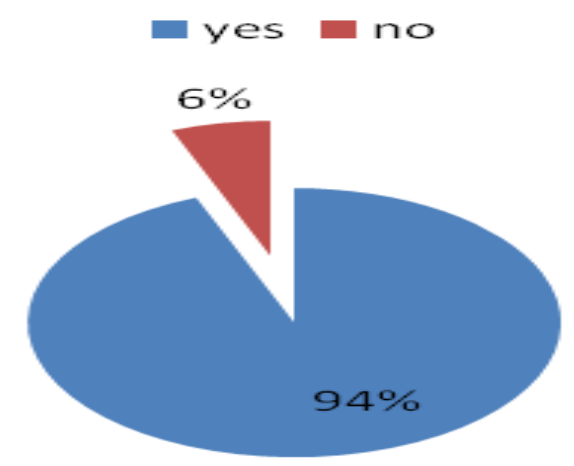

Figure 1: Response of participants to self medication.

Table 1: Demographic characteristics of the study population.

\begin{tabular}{|ll|}
\hline MBBS year & Percentage (n) \\
\hline $1^{\text {st }}$ prof & $33 \%(99)$ \\
\hline $2^{\text {nd }}$ prof & $35 \%(105)$ \\
\hline $3^{\text {rd }}$ prof & $32 \%(96)$ \\
\hline Gender & \\
\hline Male & $60 \%(180)$ \\
\hline Female & $40 \%(120)$ \\
\hline Age group & \\
\hline Below 20 & $28 \%(84)$ \\
\hline $21-23$ & $49 \%(147)$ \\
\hline 24 and above & $23 \%(69)$ \\
\hline
\end{tabular}

It was found that the prevalence of self medication is very high among medical students as they use their own experiences which they are getting in hospital environment. Internet played a key role to encourage the students for self medication (85\%) while $(78 \%)$ referred books for the same (Table 2).

Table 2: Resources of awareness about the drugs.

\begin{tabular}{|ll|}
\hline Resource & Percentage (n) \\
\hline Books & $78 \%(234)$ \\
\hline Internet & $85 \%(255)$ \\
\hline Seniors & $46 \%(138)$ \\
\hline Family and relatives & $56 \%(168)$ \\
\hline
\end{tabular}

$47 \%$ of students self medicated as they have sufficient knowledge to treat themselves, while $45 \%$ opined that trivial illnesses are not the reason to see the doctor. These two were the top most reasons for taking self medication. Rest were taking the drugs on the grounds of saving time and avoiding crowd in OPD i.e. $17 \%$ and $9 \%$ respectively whereas $5 \%$ used self medication for privacy (Figure 2).

Antibiotics were the most common class of drug self medicated drugs by the majority of participants $(80 \%)$, 
followed by analgesics (73\%) and antipyretics (66\%). It was also observed that number of other classes was also self medicated like tonics (24\%), antihistaminics (23\%), antidiarrhoeals (20\%) and antiulcer drugs (11\%). Some potentially harmful drugs were also found to be used like sedatives (5\%) (Figure 3). Out of those participants who experienced any of the side effects, $60 \%$ consulted the physician while $20 \%$ changed or stopped the medication.

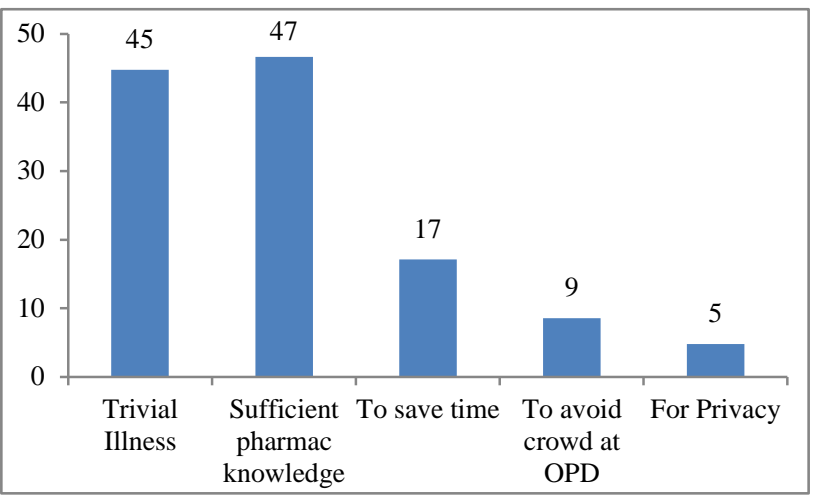

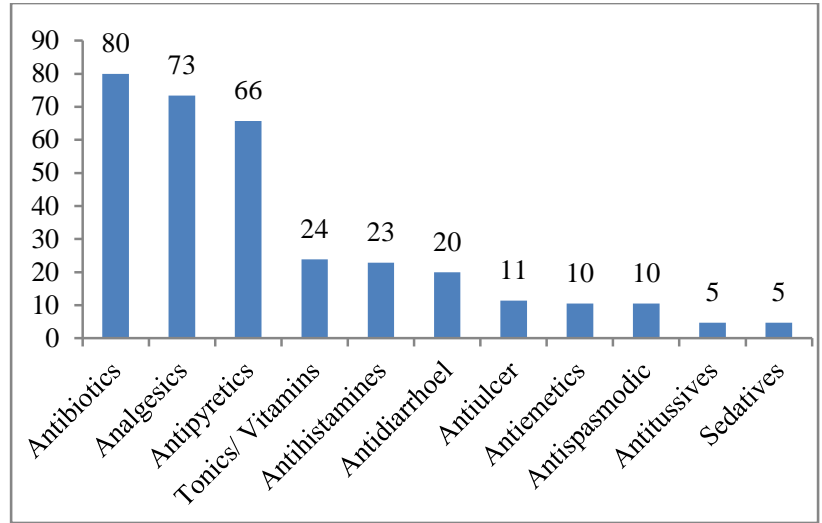

Figure 3: Comparison of categories of drugs self prescribed.

Study found that conditions prompting self medication were fever $(70 \%)$, and headache $(68 \%)$ others being pain (59\%). Cough and cold (53\%), vomiting (34\%), sore throat $(32 \%)$ and diarrhoea (27\%) (Figure 4$)$.

Figure 2: Common reasons for self medication.



Figure 4: Common indication for self medication among students.

There were different opinions of participants regarding the methods to prevent the increasing trend of prevalence of self medication among medical graduates. $29 \%$ participants had no opinion regarding this matter. $27 \%$ opined awareness and education regarding implication of self medication, $23 \%$ said supply of medicine without prescription should be prevented. Making health care facility easily available was the answer of $13 \%$ participants and enforcing strict rules against misleading pharmaceutical advertisements (5\%) (Figure 5). Selfmedication is becoming an increasingly important area within healthcare, and this study has shown that it is even more prevalent among medical students. ${ }^{4}$ It was also noted that the participants with medical background has shown more prevalence of taking self medication. Selfcare, including self-medication, has been a feature of healthcare for many years and people have always been keen to accept more personal responsibility for their health status. ${ }^{5}$

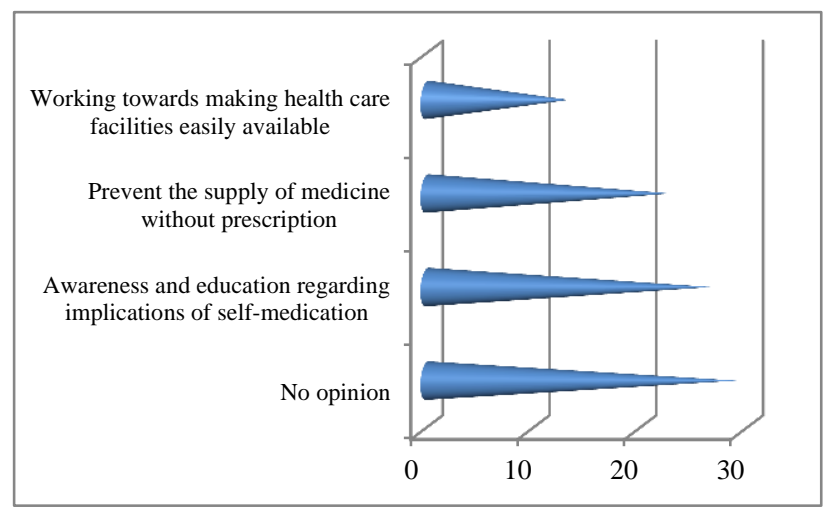

Figure 5: Perception of students regarding methods to prevent the growing trend of self-medication. 


\section{DISCUSSION}

In our study, the prevalence of self medication was found to be $94 \%$, which is somewhat in accordance with the other studies conducted in India where the prevalence of self-medication among the medical students was shown to be ranging between $57.1 \%$ and $92 \% .{ }^{6-8}$ Though it is very difficult to compare the prevalence of different studies with present study due to different demographic characteristics, different methodology, and different socioeconomic status.

Gender is considered as an important factor in selfmedication patterns among young adults including students. The prevalence of self-medication was observed to be higher among males $(60 \%)$ in our study. This differs from a previous study conducted among medical students, which showed a greater prevalence among female students (45\%) than male students $(44 \%){ }^{1}$

Among self medicators, the most common reason for it was sufficient knowledge regarding drug and disease (47\%) followed by trivial illness $(45 \%)$ which has got the similar results with previous studies. ${ }^{6,8}$ The another reason was to save time $(17 \%)$ which was the unique feature of this study. It was also found that the self medicators medicate themselves in order to avoid crowd at OPD (9\%).

In the present study, the most commonly used category of drugs was antibiotics (80\%) which is also in line with a separate study where antibiotics use was $(73 \%)$ on contrary to this in some studies most common category was analgesics $(81 \%) .{ }^{1,9}$ In our study analgesics comes to rank $2(73 \%)$ followed by antipyretics $(66 \%)$. Problems related to self medication are wastage of resources and serious health hazards such as drug dependence, adverse drug reactions and prolonged suffering. Antimicrobial resistance is another problem worldwide particularly in developing countries where antibiotics are often available without a prescription. ${ }^{10}$ Students were not afraid of using antihistamines $(23 \%)$ or sedatives (benzodiazepines) (5\%) despite of knowing all the adverse effects. These findings were in concordance with Badinger $\mathrm{S}$ et al, where use of antihistaminics was $20 \%$ and that of sedatives were $2 \%$. $^{11}$

The common reasons for self medications reported in our study were fever $(70 \%)$ that is a minor ailment followed by headache $(68 \%)$, pain $(59 \%)$, cough and cold $(53 \%)$, vomiting, sore throat $(34 \%)$ and $(32 \%)$ respectively and these findings are in concordance with the study conducted by Damodar. G, showed that the conditions like cold, headache and fever were the most common illness for self-medication. ${ }^{12,13}$

The study group cited their source of information for self medication in most cases as internet $(85 \%)$ followed by books $(78 \%)$ and seniors or classmates $(46 \%)$; this is similar to other studies, which showed medical students use their academic medical knowledge more than $50 \%$ of the time to self-medicate. ${ }^{9}$

The trend towards self-medication is increasing day by day. Our study participants suggested different ways for preventing the growing trend of self-medication like awareness and education for the same.

\section{CONCLUSION}

Thus our study demonstrates that self medication practice in students of Medical College is on the rise, the reason might be the awareness of drugs due to easy accessibility of information through books, internet pharmacy and through media too. If no strict action is taken, the incidence of adverse drugs reactions or drug interactions may go on increase with time. So essential measure should be taken to reduce the practice of self medication among students by conducting seminars, promoting the correct usage of drugs, or by delivering innovative lectures about the drugs. These activities will sensitize the students regarding irrational use of drugs and ultimately community will be benefitted.

Funding: No funding sources Conflict of interest: None declared

Ethical approval: The study was approved by the Institutional Ethics Committee

\section{REFERENCES}

1. James H, Handu SS, Khalid AJ, Khaja A, Otoom S, Sequeira RP. Evaluation of the Knowledge, Attitude and Practice of Self-Medication among First-Year Medical Students. Med Princ Pract. 2006;15:270-5.

2. Stephen S, Sukanya M, Scaria T, Sunny TT, Shettigar D. Self-medication Practices Among Undergraduate Nursing Students in South India: a cross-sectional study. Am Int J Res Sci Technol Eng Math. 2013;3:159-62.

3. Osemene KP, Lamikanra A. A Study of the Prevalence of Self Medication Practice among University students in South-Western Nigeria. Trop J Pharm Res. 2012;11:683-84.

4. Hughes CM, McElnay JC, Fleming GF. Benefits and risks of self medication. Drug Saf. 2001;24:1027-37.

5. Galato D. Joint Statement by the International Pharmaceutical Federation and the World SelfMedication Industry. Brazilian Journal of pharmaceutical Sciences. 2000;45(4):625-35.

6. Banerjee I, Bhadury T. Self-Medication Practice Among Undergraduate Medical Students in a Tertiary Care Medical College, West Bengal J Postgrad Med. 2012;58(2):127-31.

7. Sontakke SD, Bajait CS, Pimpalkhute SA, Jaiswal KM, Jaiswal SR. Comparative Study of Evaluation of Self-Medication Practices in First and Third Year Medical Students. Int J Biol Med Res. 2011;2(2):56164. 
8. Badiger S, Kundapur R, Jain A, Kumar A, Pattanshetty S. Self Medication Patterns Among Medical Students in South India. Australia's Med J. 2012;5(4):217-20.

9. Sarahroodi S, Arzi A, Sawalha AF, Ashtarinezhad A. Antibiotic Self-Medication Among South Iranian University Students. International Journal of Pharmacology. 2010;6(1):48-52.

10. Sarkar P, Gould IM. Antimicrobial agents are societal drugs: how should this influence prescribing? Drugs. 2006;(7):893-901.

11. Badinger S, Kundapur R, Jain A. Self Medication Patterns among Medical Students in South India. AMJ. 2012;5:217-20.
12. Kumar N. Perceptions and Practices of SelfMedication among Medical Students in Coastal South India. 2013;8:e72247.

13. Damodar G. Assessment of Self-Medication Practices Among Medical, Pharmacy and Nursing Students at a Tertiary Care Teaching Hospital. Indian J Hosp Pharm. 2012;49:79-82.

Cite this article as: Bhardwaj R, Sayedda K, Ahmed QS. Analysis of self medication practice among medical undergraduates: a study in tertiary care teaching hospital, Bareilly. Int J Basic Clin Pharmacol 2017;6:827-31. 